\section{Diseussion and Summary}

The results show that sodium appetite can be elicited in normal rats by treatment with aldosterone, the natural mineralocorticoid. The fact that unphysiological doses were necessary to elicit increased sodium intake under the present conditions does not preclude the possibility that endogenous mineralocorticoids may potentiate sodium appetite in an animal with a sodium deficiency-a condition which by itself can be sufficient to elicit sodium appetite (Richter, 1936) and which would provide the proper "conditioning" factors for the appetitive action of the mineralocorticoids. The necessity for using high doses to induce voluntary sodium intake in the absence of need (i. e., in a physiologically unreceptive animal) is understandable. In addition it is very probable that under the present conditions the mineralocorticoid may inhibit the excretion of ingested sodium and thus elevate body sodium levels. Presumably a high level of circulating mineralocorticoid would be necessary to overcome the demonstrated tendency of a sodium overload to inhibit the intake of sodium (Beilharz \& Kay, 1963; Stellar et al, 1954).

\section{Comment}

Kimmel apparently failed to realize that the conclusion he questioned rested on more than just a significant interaction. It was specifically stated in the article (Psychon. Sci. , 1964, 1, 139-140) that the extinction curve for No-Shock-No Shock started above and ended below the extinction curve for Shock-No Shock. Inspection of the curves, together with the given $\mathrm{F}$ for interaction, should have made it clear that this cross-over effect was real. To remove any remaining doubt, the interaction was recomputed omitting the first trial block of extinction. The $\mathrm{F}$ for interaction, quadratic was 6.31 , $\mathrm{df}=1 / 14, \mathrm{p}<.025$. Since the two groups were nearly equal on the second trial block of extinction, this shows that the Shock-No Shock group was more resistant to extinction.

\section{References}

BEILHARZ, S., \& KAY, R. N. B. The effects of ruminal and plasma sodium on the sodium appetite of sheep. J. Physiol., 1963, 165, 468-483.

RICE, K. K., \& RICHTER, C. P. Increased sodium chloride and water intake of normal rats treated with desoxycorticosterone acetate. Endocrinology, 1943, 33, 106-115.

RICHTER, C. P. Increased salt appetite in adrenalectomized rats. Amer. J. Physiol., 1936, 115, 155-61.

STELLAR, E., HYMAN, R., \& SAMET, S. Gastric factors controlling water-and salt-solution-drinking. J. comp. physiol. Psychol., 1954, 47, 220-26.

WOLF, G. Sodium appetite elicited by desoxycorticosterone. Unpublished doctoral dissertation, Yale Univer., 1964.

\section{Note}

1. Work in this study was supported by grant MH02949 from the National Institute of Mental Health, United States Public Health Service. The author is thankful to Dr. Robert Gaunt, Ciba Pharmaceutical Co., for supplying the aldosterone.

Kimmel's remaining comments, which concern minor aspects of the statistical analysis, do not seem well taken. There was obviously good a priori reason to test for the linear component of shock. The shock levels were chosen on the basis of previous results to be about equally spaced in their effect on behavior. The power of the experiment is increased to the extent that this choice is successful. (Of course, the use of the specific comparison represented by the linear component does not require equal spacing of the independent variable.) Extraction of the linear and quadratic trends of the interaction would be expected to increase the power of that test but was unnecessary since the overall interaction F was highly significant.

Eileen B. Karsh

Drexel Institute of Technology 